\title{
Digital Storytelling in Kindergarten: An Alternative Tool in Children's Way of Expression.
}

\author{
Eleni Papadimitriou \\ Teacher of Pre-School Education,Department of Primary Education, \\ University of Thessaly, Volos, Greece, \\ E-mail: elpapadi@uth.gr

\section{Alexandros Kapaniaris} \\ PhD Candidate in Folklore, Department of Science Education and Educational Design, \\ University of the Aegean, Rhodes, Greece \\ E-mail: a.kapaniaris@aegean.gr \\ Dimitris Zisiadis \\ Research Associate, Department of Computer \& Communication Engineering, \\ University of Thessaly, Volos, Greece \\ E-mail: dimitris@uth.gr

\section{Evangelia Kalogirou} \\ M.Ed. Candidate, University of Nicosia, Cyprus \\ E-mail: lilia.kalogirou@yahoo.gr
}

\section{Doi:10.5901/mjss.2013.v4n11p389}

\section{Abstract}

\begin{abstract}
This paper refers to Digital Storytelling as an alternative tool enhancing children's way of expression in kindergarten classroom. Storytelling is a global culture depicting the way people live, feel and interact in life. Especially in early childhood storytelling springs naturally in children's play helping them to exercise a great variety of skills. Nowadays, advances in technology offer the opportunity to create a new form of storytelling, namely digital storytelling. The idea of creating a digital story is based on processes similar to those used in traditional stories. On the other hand the story is supplemented with various types of multimedia content. Meaningful integration of technology into kindergarten gives children the opportunity to create their own digital stories and thanks to multimedia technology children are enabled to become co-authors in the story writing process. In this paper a teaching experiment that took place in the kindergarten of an urban area in Greece on February 2012 is described. The teaching experiment lasted three weeks. We present the attempt of creating an educational framework in which the children were given the opportunity to combine various elements and Information Computer Technology tools, in order to express themselves and give birth to a digital story. It was found that children were engaged to the whole process, showed responsibility, self-confidence and they also exercised cooperation skills.
\end{abstract}

Keywords: Storytelling, Digital Storytelling, ICT, Early Childhood, cooperation skills

\section{Introduction}

According to Booth, stories constitute a fundamental way of organizing human experience. We look for our stories in other peoples' stories. Therefore_storytelling is a way to look back in time in order to move forward and it is an active process (Booth, 1994). According to Culler, stories are the main way for anyone to apply meaning to things, either by reflecting his own life as a process that leads somewhere, or by saying to himself what is happening in the world. Scientific explanations reveal the meaning of all through laws, but life generally is not like that (1997:82).

Storytelling is reformed to digital storytelling with the introduction of multimedia in everyday life. Many definitions exist for digital storytelling, however they all converge to the combination of storytelling with a variety of digital multimedia like image, sound and video. Almost every digital story combines graphics, text, oral storytelling recordings, video and music in order to present a specific subject. Digital storytelling, just like traditional storytelling, revolves around a specific 
topic and often involves a concrete meaning. Stories typically last a couple of minutes and they may either refer among other things to personal experiences and historical events or they can provide information or guidance on a particular topic.

According to Lathem, digital storytelling is defined as «the combination of traditional oral storytelling with 21st century multimedia and ICT tools». It is a process that combines digital media in order to enrich and enhance written or spoken stories (Lathem, 2010: 2286-2291). Meadows concludes that even if storytelling is not something new, digital storytelling is a novelty (Meadows, 2003: 189-193). For Pedersen digital storytelling is a relatively new form of art that uses music, image, video and storytelling to create stories about life, work and human experiences that share through the Internet (Pedersen in Sadik, 2008: 489). Meadows believes that digital storytelling is the social practice to tell short multimedia stories from data derived from low cost digital cameras, non-linear authoring tools and computers (Meadows, 2003: 189-193). Finally, the International Organization for Digital Storytelling defines digital storytelling as the modern counterpart of the ancient art of storytelling. Storytelling has evolved through history as a way of sharing knowledge, wisdom and values. The seven key components of digital storytelling are: 1) main idea, 2) dramatic question, 3) emotional content, 4) the gift of "voice", 5) the power of background music, 6) economy and 7) pace (Robin, 2008: 220228, The Digital Storytelling Association, 2002).

\section{Digital Storytelling in Education}

Digital storytelling, according to many researchers, is a simple yet dynamic method that helps students understand the complicated, without rules world of experiences through story composition (Bruner, 1990" Gils, 2005 in: Sadik, 2008: 489). Compared to traditional storytelling, the audience of digital storytelling is not passive but rather patricipates as coauthor that interacts and shapes the story (Dorner et al. 2002: 45-55). Digital storytelling encourages children to «organize and express their ideas in a personal and meaningful manner», according to research (Sadik, 2008: 490).

Jonassen and Hernandez-Serrano suggest three ways to support learning through storytelling. First, they can be used as examples of notions or values that have been taught with direct learning. Second, they can be presented as problems to be solved by the students. Third, stories can have an advisory role and help students solve problems (Jonassen kaı Hernandez-Serrano, 2002: 65-77).

As digital storytelling promotes an in-depth understanding of texts, it also encourages children to become competent in terms of the technical aspects of the language, and just 'play' with words and familiarize with the writing process. Studies reveal that children gradually increase their desire to experiment with the language and make changes when involved in digital storytelling (Hull \& Katz, 2006: 43-81' Ware, 2006: 45-54' Ware \& Warschauer, 2005: 437). Moreover, digital storytelling increases the chances for students to be engaged in problem solving and familiarize with technology through practice and experimentation (Kajder, 2004: 64-68' Robin, 2008: 220-228' Ware, 2006: 45-54).

Digital storytelling requires children to compose information, to enhance their creativity, conduct research and exercise critical thinking (Hull \& Katz, 2006: 43-81" Ohler, 2008: 54" Ware, 2006: 45-54 ' Ware \& Warschauer, 2005: 436).

Naturally children can use traditional storytelling to express themselves. However children awareness and confidence to tell an interesting story that will grasp the audience's attention is increased through digital storytelling. (Ware, 2006: 45-54). In addition to that, combining music with personal storytelling boosts self-control over one self's presentation to the world (Hull \& Katz, 2006: 43-81).

Researchers suggest that suitable technology integration in the classroom is a critical condition for success for teachers and students as well. The authentic effort is crucial in design, flow of the story and filming of each activity, which may be related to technology in order to comprehend the result of a successful learning process (Pitler, 2006: 38-42).

One must always have in mind that «the story must be in the foreground while keeping technology in the background» (Bull \& Kajder, 2004: 47). The focus should remain in the writing process and not in technical results (Ohler, 2008: 56). As far as the actual story is concerned, the definition of the Seven Components of Effective Digital Stories is crucial according to researchers, like Bull \& Kajder, Ohler and Sadik. Teachers should provide beforehand brief explanatory guidance and examples of all components in every stage of the authoring process:

1. Tellability: selection of a worth telling story.

2. Initial scenario: a draft of the story helps basic ideas to evolve. It can also be redefined after input from the children.

3. Storyboard: a basic structure of the story complements the initial scenario. Storyboarding reveals the content of the story. Image selection, slides text input and transitions are all defined in this step. 
4. Discussing the scenario with children and recapitulation: this process ensures that focus is kept on the story, concepts are clarified and proper words are chosen. The message of the story is revealed along with the emotions emerging from the story.

5. Video editing: image and frame setting in the video editor are performed in this step. The best way to organize material is to create a folder with all images of the story.

6. Voice insert: voice of the narrator is inserted at this stage. The addition of children's voices enhances the digital story. Narration enables pace control in order to present the meaning of the story in the best way.

7. Special effects and transitions are added in this step. Special effects have an added value depending on the type of story (Bull \& Kajder, 2004: 46-49" Kajder, 2004: 64-68" Ohler, 2008: $133^{\circ}$ 'Sadik, 2008: 490).

Teachers who wish to use digital storytelling in the teaching process should bear in mind that technology integration is successful when it includes practices, techniques, such as children engagement in discussions, collaboration, critical thinking, and feedback at all stages of the project, i.e. before, during and after (Pitler, 2006: 38-42).

\section{Methodology of Research}

\subsection{Research Type/Framework}

For the implementation of the current research the teaching experiment was chosen, which took place in a traditional urban nursery school in Greece in a classroom consisted of 19 children. The material and technical support exploited for the production of digital stories in the classroom included a computer, speakers, digital camera and webcam, as well as raw materials and materials for experiential activities-dramatization. At the same time, the activities were supported through a blog created for this purpose (http://elmer-project.blogspot.com/2011/01/blog-post_9004.html). Finally, Vegas Pro 11 video editor (http://www.sonycreativesoftware.com/vegaspro) was used for digital story processing.

\subsection{Research Mission}

To investigate preschool/early primary school childrens' interest in digital storytelling.

\subsection{Research Goals}

a) To investigate children interaction and children-teacher interaction during the digital story development process.

b) To investigate preschool children motivation and their engagement with the activities within a learning framework that combines raw material, experiential activities and ICT tools.

\subsection{Research Assumptions}

a) Digital story development promotes children interaction among them as well as with their teacher.

b) Digital storytelling development motivates children's interest in storytelling.

\subsection{Research Type}

Teaching experiment was the chosen approach in this case, as it allows for systematic exploration and interpretation of the learning process, but also «experimentation» in the teaching framework (Chronaki, 2009: 605).

\section{Sample Selection}

The teaching experiment took place in a kindergarten classroom, consisting of 19 children, 13 of them are infants and 6 of them are in preschool. There are 10 girls and 9 boys in this class. The particular needs and characteristics of preschool and early primary school age was an important factor for the selection of our sample. Due to the size of the sample, results apply only to the present research carried out under the specific conditions and cannot be generalized in any way (Cohen, Manion, \& Morrison, 2008:170). 


\section{Data Collection Tools}

Data collection tools are the semi-structured group interviews, observation, notes and filming of the activities.

\subsection{Data Processing and Analysis Method}

The qualitative data obtained were organized per subject, according to children interaction and their interest in storytelling, followed by classification by induction into categories. Then they are tested and examined in relation to the assumptions of the research (Roberts-Holmes, 2008:155-160, Cohen, Manion, \& Morrison, 2008:251).

\section{Research Validity and Reliability}

Subjectivity of the researcher, difficulty in isolating the factors that influence the experiment, subjective interpretation of psychological phenomena, difficulty in external factors recording and analysis, limited sample size, sample heterogeneity and lack of a control group in the conditions of the research are defined as inherent constraints of the teaching experiment (Dina van Hiele in: Briasouli, 2010: 32).

\section{Research Ethics}

Parents were informed beforehand for the activities and the research mission. They all gave their consent. Moreover, an initial discussion with the children made it clear for them that they will conduct different activities with their teacher/researcher at the end of which they will comment whether they liked it and whether they would like to do it again (Roberts-Holmes, 2008:63)

\section{Application of the Teaching Experiment}

Project title: «Shall we play with Elmer, the pied elephant?»

Class: 2nd traditional Kindergarten of Volos

Subjects: Cross curriculum approach with elements from Curriculum on Audio-visual expression in Elementary School, as well as the Cross thematic Curriculum Framework for Compulsory Education and the Kindergarten Teacher's Guide.

Duration: three school weeks.

\section{Research Phases}

The research was divided into three distinct phases: the investigation phase, the phase of introduction to the scenario and the implementation phase. The duration of each phase of the research is a school week, therefore the experiment lasted three weeks.

\subsection{Phase A'- 1st Week (Jan 9-13, 2012)}

During the first week children get to know the teacher-researcher and they familiarize with the use of digital camera and webcam. In parallel, semi-structured group interviews in groups of two and three were organized, in order to detect children views and knowledge about the new technological tools they would use during the activities.

This is a very interesting point, as for some children these tools are unknown or their use is forbidden. Even if their parents had digital cameras and webcams they didn't allow their children to use them fearing that the children would mess things up or even ruin them.

During the interview, children were asked to identify the objects in the researcher's hands and their potential uses and if they were capable of using them. All children recognized the digital camera but they were not aware of its capabilities. Some children didn't recognize the webcam because of its small size, whereas professional cameras used in social events (weddings, baptisms) are quite large. The vast majority of the children could not correlate these digital tools with classroom activities or storytelling. We present below a brief part of an indicative dialogue: 


\subsubsection{Dialogue 1: 3rd group (P., N., M.)}

... Researcher: What do you think are these items? (She holds a digital camera and a webcam)

$P$.: Digital camera.

M. Yes, it is a digital camera. This one too (points at the webcam).

N.: What is this?

P.: Can I take some photos? Let me take some photos!

Researcher: Sure $P$., you can take some photos as soon as we finish our discussion, ok?

P.: I want now!

N.: I want too!

Researcher: First we will discuss a little while for the tools I hold in my arms and then I will show you how you can take photos so that you can try and take whatever photo you like, agree?

M.: Yes. I know how to take photos.

P.: Me too!

N.: Me too! But my dad doesn't let me to!

M.: Mine let me a bit, once, a little bit.

P.: Mine doesn't let me either! He doesn't let me!

N.: We also have one in school ... (he runs and grab the toy camera from the toy basket) can I take a photo of you? (He poses and gets excited when he takes some «photos»)...

\subsection{Phase B' - 2nd Week (Jan 16-20, 2012)}

\subsubsection{1st activity: Monday, Jan 16, 2012: 1st class period.}

Title: Narrating Elmer's story.

Learning objectives: a) Children navigation in the relevant blog, b) Children listening Elmer's story. (Literature), b) Fostering narrative speech by giving different versions of the continuity and the end of the story (Language, speech).

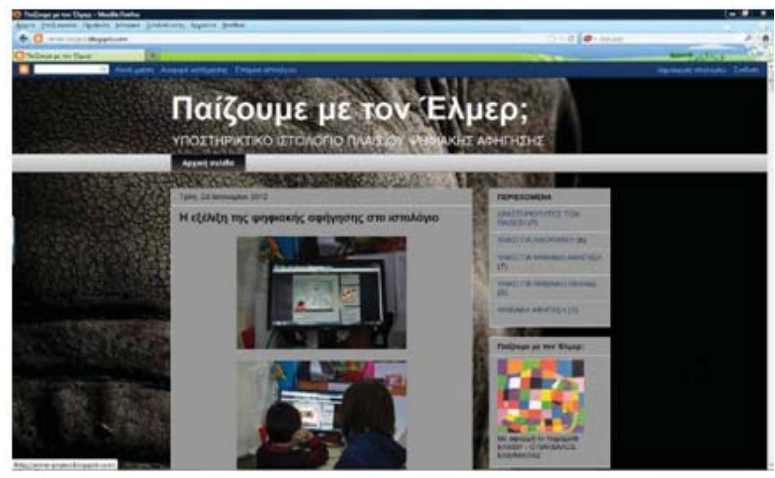

Figure 1: Digital storytelling blog.

The researcher initially created the relevant blog, where pictures and video from other children's work on the story of Elmer were posted. Then, at a later date, children's projects were also posted.

The teacher shows the video to the children, where images from the book become «alive» through the animation of the story. Children are asked to put the words in the bubbles in every frame of the story they see, creating a summary of the story they heard. The teacher had to coordinate children views but generally the children managed to recreate the basic skeleton of the story. Children seem tired by this process so the teachers do not insist and reward verbally all children for their efforts.

\subsubsection{2nd activity: Tuesday, Jan 17, 2012: 1st class period.}

Title: Where is Elmer? Our story!

Learning objectives: a) Children narrating a new adventure in the jungle, b) Filming their story, so that c) they are 
able to produce a simple audio-visual narration (daily process) with successive images, $d$ ) realize that the image series form a single narrative set.

In this activity a "magic box" was chosen as a starting point. More specifically, the teacher-researcher comes in the classroom holding a cheerfully wrapped box that aims to excite children's imagination. Immediately children make different assumptions about its content. They interact really positively and they start arguing with each other about what might be hidden in the magic box. The teacher encourages children to create a new adventure story with Elmer, based on animals that are brought out of the box. The teacher-researcher provides the beginning of sentences like: «another beautiful day dawned in the jungle! Elmer has not returned yet... so,...». The teacher attempts to address questions during this process, like: «what can we do in order to...? What would change if...? What do you think it will happen if...? If this is as you say, what will happen when...?». This proved to be quite difficult, possibly due to the fact that this was the first effort for children to create a story exclusively on their own, as the teacher herself already mentioned.

At the same time an attempt to create a story map according to Ohler. Children aided by their teacher produce a «map» of the story containing the main figures, the heroes of the story and its core, the heart of the story which resides in the centre of the map. Children select the scenes they wish to dramatize or to visualize based on this map. The dramas and the visualizations form the main material of the digital storytelling (Ohler in: Kotronidou \& Toziou, 2011:27-28)

\subsubsection{3rd activity: Wednesday, Jan 18, 2012: First class period.}

Title: We look for Elmer!

Learning objective: Children recreating, dramatizing their adventure using material and furniture in the classroom.

As a starting point, the teacher displays the video of the story made by children and suggests giving «life» to it.

During implementation of the main part of the activity, using the standard method followed by free improvisation, children narrate while giving 'life' with their bodies on the adventure of elephants and other jungle animals, searching for their friend and "pass "through different obstacles. Meanwhile, a small voluntary group is responsible for filming the event. Children inform the teacher on what they want to film. This cooperation is mandatory in order to achieve the desired result. Children seem to enjoy their «director» role, explaining to the teacher where she has to focus. This role exchange is a new experience for the children in which they respond with excitement. So, children offer the «view» and the teacher does the technical part that requires stability that children can't achieve in this age. Children defined the plot of the dramatized story.

\subsubsection{4th activity: Thursday, Jan 19, 2012: First class period.}

Title: We draw frames from our adventure!

Learning objectives: a) Children visualizing their adventure in any way they can, b) posting results in the blog.

The teacher-researcher displays the video from the story of the children and suggests creating successive frames, to make their main storyboard.

Children, after discussion, chose their main story frames that they feel mandatory to tell their adventure. Next, the teacher with the children's help digitizes the material and helps them with their storyboard. In the end, children with the teacher's help verify image and speech correlation (frame descriptions).

Throughout the activity children respond and interact positively. The fact that they are accustomed in such processes, where they visualize scenes they liked the most among stories told by their teacher in the classroom contributes to the positive attitude they maintain.

\subsection{Phase C'-3rd Week (Jan 23-27, 2012)}

Third research phase - digital storytelling development

Three more classroom visits were made during this phase, where children divided in groups discussed the ways to display their story to the neighbouring classroom or to their parents, by using the dramatizations along with their pictures.

At first it was made clear to the children that the teacher-researcher could use an ICT tool for video-picture combination. This was the hardest part of the process. Children proved to be incapable of comprehending the final outcome of this process («product»). However children showed they understand the suggestion to «make a movie» of the story.

Storyboard proved to be valuable from this point on. Children formed groups to decide about each frame of the 
storyboard. The teacher-researcher and the kindergarten teacher were guiding children during this phase. The process went smoothly from the point where each team comprehended the way to visualize every frame, which is to select either a video from the drama or a particular drawing.

Vegas Pro 11 software was used to create the digital story based on the frames selection from the children groups. The teacher-researcher added writing in the digital story where it seemed necessary. Finally, children watched their digital story in the kindergarten projector and their reactions testify they liked the result.

\section{Discussion}

The initial target of this teaching intervention was to offer new ways of expression to the children, namely storytelling. By making use of dramatization as the digital story material along with children's drawings, the result was pleasant especially for the children participating.

The experiment in the kindergarten classroom revealed that preschool and early primary school children respond to such a learning experience. Teaching experiment was chosen since the point of interest was the ability to interpret the learning process and the «experimentation» in the teaching framework and not the learning result alone.

It was found that there is a positive interaction in line with the original goals set, among students and with their teacher as well during the digital story development process. Furthermore, it was found that children are motivated and engaged in the activities within the learning context that combines materials and experiential activities along with new ICT tools.

As far as the research assumptions are concerned, it was verified that digital storytelling development encourages interaction between students and the teacher as well. However, no evidence was found to indicate that the creation of digital storytelling motivates children's interest in storytelling. More time is required for observation of children behaviour and their classroom interests, beyond the timeframe of teaching intervention through digital storytelling, in order to evaluate whether children's interest on storytelling is affected. This proposal aimed to focus on the experiential, cooperative and mainly playful learning. At the same time children were active composers of the learning framework. This boosted children confidence, enhanced cooperation and revealed possibilities that could never emerge through traditional activities. Children not only managed to make their own Elmer story, but they animated it with their personal way of expression.

It is highlighted that the teacher in this process provides the "spark" and tools and helps students using them, but at every stage of the process it is the children themselves that give meaning to what they do, play and create. So children and teachers are companions in the same learning process, equal and complementary to each other.

\section{References}

Booth, D. (1994). Story Drama. Canada: Pembroke Publishers Limited.

Briasouli, A., (2010). Dina Diege Van Hiele-Geldof's teaching experiment. Analytical approach of her work and possibilities to increase the geometric concept by incorporating elements of art. Thesis, under the supervision of: Pournari, M., Koleza E., Mprouzos, A., Ioannina, Pp.32.

Bruner, J. (1990). Acts of meaning. Pp. 489. Cambridge, MA: Harvard University Press.

Bull, G., \& Kajder, S. (2004). Digital storytelling in the language arts classroom. Learning \& Leading with Technology, 32 (4), 46-49.

Chronaki, A., (2010). «Teaching Experiment»: studying learning development in the context of teaching in Pourkos, M., Dafermos, M. (sup.) (2010). Qualitative Research in Psychology and Education: epistemological, methodological and ethical issues. Pp. 605. Athens: Topos.

Cohen, L., Manion, L., Morrison, K. (2008). Research Methods in Education. pp. 170,251. Metaihmio: Athens

Culler, J. (1997). Literary theory. A very short introduction. pp.82. N.Y.:Oxford University Press.

Dorner, R., Grimm, P., \& Abawi, D. F. (2002). Synergies between interactive trainingsimulations and digital storytelling: A componentbased framework. Computers \& Graphics, 26, 45-55

Gils, F. (2005). Potential applications of digital storytelling in education. In 3rd Twente Student Conference on IT, University of Twente, Faculty of Electrical Engineering, Mathematics and Computer Science, Enschede, February 17-18. In Sadik, A. (2008). Digital storytelling: A meaningful technology-integrated approach for engaged student learning. 56 (pp.490). Educational Technology Research and Development.

Hull, G., A. \& Katz, M., L. (2006). Crafting an agentive self: Case studies of digital storytelling. Research in the Teaching of English, 41 (1), 43-81.

Jonassen, H., Hernandez-Serrano, J. (2002). Case-based reasoning and instructional design using stories to support problem solving. Educational Technology Research and Development, 50 (2), 65-67.

Kajder, S. B. (2004). Enter here: Personal narrative and digital storytelling. English Journal, 93 (3), 64-68. 
Kotronidou, I., Toziou, T. (2011). Digital storytelling in School. The use of ICT in cultivating students' multiliteracies and communication skills. Athens: Ziti, 27-28.

Lathem, S.A. (2005). Learning communities and digital storytelling: new media for ancient tradition. In C. Crawford et al. (Eds.), Proceedings of Society for Information Technology \& Teacher Education International Conference, 2005 (pp. 2286-2291). Chesapeake, VA: AACE.

Meadows, D. (2003). Digital storytelling: Research-based practice in new media. Visual Communication, 2(2), 189-193.

Ohler, J. (2008). Digital storytelling in the classroom: New media pathways to literacy, learning, and creativity. Pp. 54, 56, 133. Thousand Oaks, CA: Corwin Press

Pedersen, E. (1995). Storytelling and the art of teaching. FORUM, 33(1). In Sadik, A. (2008). Digital storytelling: A meaningful technology-integrated approach for engaged student learning. Educational Technology Research and Development, 56, 489.

Pitler, H. J. (2006). Viewing technology through three lenses. Principal, 85 (5), 38-42.

Roberts-Holmes, G. (2008). Doing your early years research project. Pp.63, 155-160, Sage: London

Robin, B. (2008). Digital Storytelling: A Powerful Technology Tool for the 21st Century Classroom. Theory Into Practice, 47, $220-228$. Retrieved January 12, 2012, from http://www.tandfonline.com/doi/abs/10.1080/00405840802153916?journal Code=htip20

Sadik, A. (2008). Digital storytelling: A meaningful technology-integrated approach for engaged student learning. Educational Technology Research and Development, 56,490.

Ware, P. D. (2006). From sharing time to showtime! Valuing diverse venues for storytelling in technology-rich classrooms. Language Arts, 84 (1), 45-54.

Ware, P.D. \& Warschauer, M. (2005). Hybrid literacy texts and practices in technology-intensive environments. International Journal of Educational Research, 43(7-8), 436 